\title{
XXXVIII. On an instrument for photometry by comparison, and on some applications of it to important optical phænomena
}

\section{R. Potter Jun. Esq.}

To cite this article: R. Potter Jun. Esq. (1832) XXXVIII. On an instrument for photometry by comparison, and on some applications of it to important optical phænomena, Philosophical Magazine Series 3, 1:3, 174-181, DOI: 10.1080/14786443208647867

To link to this article: http://dx.doi.org/10.1080/14786443208647867

曲 Published online: 01 Jun 2009.

Submit your article to this journal $₫$

Џll Article views: 3

Q View related articles $\longleftarrow$ 


\section{Mr. Potter on a new Photometer by Comparison, and}

nomical purposes we merely change its direction, taking it away from one place and throwing it upon another; and in all such operations light is invariably lost: but if we can stimulate the retina and render it more sensible to a weak light by the mode of its application, we obtain the very same effect as if we had used a more powerful beam. The experiments which I have made on this subject have been more successful than I could have expected; and I hope to be able on some early occasion to submit them to the Association.

XXXVIII. On an Instrument for Photometry by Comparison, and on some Applications of it to important Optical Phanomena. By R. PoTre R, Jun. Esq.*

WHEN engaged in examining the phænomena of the colours of thin plates in the form of what are generally denominated Newton's rings, I was surprised to find that the rings were so distinct in the transmitted light, and particularly when homogeneous light was used. These rings are now generally allowed to be produced, by the agency of the light which has been twice reflected at the surface of glass, under an incidence very nearly perpendicular.

Photometry had taught me that most of the common sorts of glass reflect about $\frac{1}{3}$ th of the light incident upon them in this case; and we should expect two reflections to give an intensity of $\frac{1}{50}$ th of $\frac{1}{30}$ th, or $\frac{1}{90}=$ th of the first intensity. Now it requires very little consideration to see, that the presence or absence of so small a quantity of light is quite beyond detection by the eye, and experiments are easily executed by which it may be proved.

The difficulty of accounting for so great an effect being produced in a pencil of light, by so small a proportion of it, renders almost equally inadmissible every hypothesis which has yet been proposed to account for the whole phænomena of thin plates. On the doctrine of fits of easy reflection and transmission, which many experiments, otherwise, show must be dispersed with, even in the theory that light is caused by an emitted matter, this difference of the intensity of the dark and bright rings in the transmitted light is not to be satisfactorily accounted for. The theory that light consists of undulations in a subtile æther, gives scarcely any more admissible reason for the rohole appearances, than the other. For in this theory the intensity of the light being taken as the amount of vis viva in the vibrating molecules, the modification which could be intro-

* Communicated by the Author. 
duced by the interference of $\frac{1}{0} \sigma$ th part of the whole vis viva, of the transmitted light, must be allowed, on all mechanical considerations, to fall exceedingly below so distinct an effect as that which we witness.

These considerations induced me to think upon the possibility of determining the relative intensities of the light in these dark and bright rings. This is not so difficult a problem as it at first sight appears to be; for though we may perhaps never expect to measure the light in the rings directly, yet it will be seen that if we can form variable appearances where we know the intensities of the lights, we may so vary them that they may form a representation of the phænomena we are considering; and then the only difficulty to be encountered is that of the eye judging with sufficient precision and accuracy, when the artificial is a correct representation of the natural effect. In experiments of this sort the only resource is that of repeated practice, by which the eye acquires a power of judging with an exactness far beyond what would be expected at the first trial.

There are evidently many ways of producing appearances where the intensities of the illuminations may be subjected to measurement and calculation. The instrument $I$ have executed for the particular purpose above mentioned, is very manageable, but can only be used in the day-time, and in a particular state of the sky; that is, when it is either misty or uniformly overcast with clouds, so that a uniform illumination may be afforded to a piece of pasteboard, which is an essential part of the instrument.

The instrument $I$ have used consists of a flat board of about 16 inches in length and 12 inches in breadth: on this board I fix edgewise a rectangular piece of pasteboard of about $23 \frac{3}{4}$ inches in length and $3 \frac{5}{3}$ inches in breadth. The edge of this pasteboard is fixed along a semicircle described on the board, as shown in the figure. In the centre of the circular arc is a pin, as at $a$, upon which turn the two arms $a b$ and $a c$. Attached to each of these arms is a piece of crown-glass, which has been

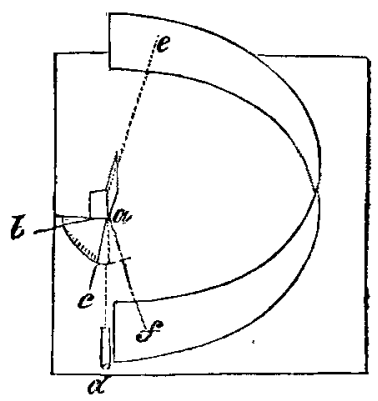
ground flat and polished; and afterwards covered at the further surface with black varnish to prevent reflection there. These pieces of glass are so fixed as when moving with the 


\section{Mr. Potter on a new Photometer by Comparison, and}

arms round the pivot, to remain always perpendicular to the plane of the board ; and hence, to an eye placed as at $d$, these glasses will reflect images of some portions of the surface of the pasteboard. If this surface is everywhere equally illuminated, the brightness of the reflection in the glasses will depend only on their inclination to the visual rays: thus when either glass reflects to the eye, the light from the part of the pasteboard almost opposite, or from $e$, the reflection will be very strong, and it will be weakest when the incidence is nearly perpendicular, or when the glass shows to the eye the part near $f$. Having a fixed position for the eye, or a tube through which to view the glasses, we easily determine the angle at which the light entering the eye is incident on the glass, by having a quadrant round the pivot graduated, and showing the inclination of the arms to the direction of the light.

It will now be evident that to produce a representation of the transmitted rings, we may view two narrow stripes of the glasses, covering any superfluous parts with blackened paper, and move the arms carrying them until the relative intensities of the reflections are sensibly the same as the relative intensities in the rings. Then knowing the angles of incidence upon the glasses, we can calculate the intensities of the light from a formula, which I have deduced from experiments, and published in the Edinburgh Journal of Science. The apparatus producing the rings with homogeneous light should also be attached to the board, or otherwise kept so conveniently that we may view them or their representatives alternately without any considerable space of time intervening; and the pasteboard should be coloured to the same tint as the homogeneous light made use of, to produce a more correct representation, and to prevent the eye from being deceived by any difference of colour.

The lights $I$ have used in these experiments are a good homogeneous green, produced by a solution of arsenite of copper (Scheele's green) in muriatic acid, and a very perfectly homogeneous red, produced by a solution of iodine in hydriodic acid; this last solution gives most probably a purer colour than can be obtained of equal intensity by any other medium. I keep the solutions in small cut-glass phials with flat sides.

With the green light I found the rings produced by a lens of long focus* pressed upon a plane surface, to be represented

* I do not know exactly the curvature of this lens, but believe it to be to a radius of 15 or 16 feet. 
in the photometer at the incidences given in the first and second columns of the following Table; the third and fourth give the quantities of light reflected; and the fifth the ratio of these quantities, the smaller one being taken as unity.

\begin{tabular}{|c|c|c|c|c|}
\hline $\begin{array}{c}\text { Glass for the } \\
\text { dark Ring } \\
\text { being set at } \\
\text { Incidence : }\end{array}$ & $\begin{array}{c}\text { Glass for the } \\
\text { bright Ring } \\
\text { requires to be } \\
\text { Incidence : }\end{array}$ & $\begin{array}{c}\text { Dark Ring } \\
\text { contains: }\end{array}$ & $\begin{array}{c}\text { Bright Ring } \\
\text { contains : }\end{array}$ & $\begin{array}{c}\text { Ratio, the } \\
\text { dark Ring } \\
\text { being taken } \\
\text { as unity. }\end{array}$ \\
\hline $20^{\circ}$ & $63^{\circ}$ & $3 \cdot 83$ & $9 \cdot 06$ & $2 \cdot 36$ \\
20 & 62 & $3 \cdot 83$ & $8 \cdot 66$ & $2 \cdot 26$ \\
30 & 67 & $4 \cdot 18$ & $11 \cdot 15$ & $2 \cdot 66$ \\
30 & 66 & $4 \cdot 18$ & $10 \cdot 54$ & $2 \cdot 52$ \\
40 & 69 & $4 \cdot 76$ & $12 \cdot 59$ & $2 \cdot 64$ \\
40 & 68 & $4 \cdot 76$ & $11 \cdot 83$ & $2 \cdot 48$ \\
50 & 71 & $5 \cdot 81$ & $14 \cdot 4 \cdot 1$ & $2 \cdot 48$ \\
50 & 71 & $5 \cdot 81$ & $14 \cdot 41$ & $2 \cdot 48$ \\
\hline
\end{tabular}

With the red light I obtained as in the next Table. The ratio of the intensities of the bright to the dark rings is here much greater than with the green light. I had expected it to be so in some degree, from the greater purity of the light, but not nearly to the extent which I found it. I repeated the first trials I made, very often, before I noted them down, and did not do so until I found clearly that the eye was not satisfied with any less difference.

\begin{tabular}{|c|c|c|c|c|}
\hline $\begin{array}{c}\text { Glass for the } \\
\text { dark Ring } \\
\text { being set at } \\
\text { Incidence : }\end{array}$ & $\begin{array}{c}\text { Glass for the } \\
\text { bright Ring } \\
\text { requires to be } \\
\text { at Incidence: }\end{array}$ & $\begin{array}{c}\text { Dark Ring } \\
\text { contains : }\end{array}$ & $\begin{array}{c}\text { Bright Ring } \\
\text { contains: }\end{array}$ & $\begin{array}{c}\text { Ratio, the } \\
\text { dark Ring } \\
\text { being taken } \\
\text { as unity. }\end{array}$ \\
\hline $30^{\circ}$ & $70^{\circ}$ & $4 \cdot 18$ & $13 \cdot 44$ & $3 \cdot 21$ \\
30 & 71 & $4 \cdot 18$ & $14 \cdot 41$ & $3 \cdot 44$ \\
40 & 73 & $4 \cdot 76$ & $16 \cdot 74$ & 3.51 \\
40 & 74 & $4 \cdot 76$ & $18 \cdot 16$ & $3 \cdot 81$ \\
\hline
\end{tabular}

To calculate the intensity of the light in the third and fourth columns, I have used the formula which I have found for crown-glass in the essay above referred to; namely, of every 100 rays incident, those reflected are equal to $a+\frac{c^{2}}{r+b-x}$, where $a, b, c$ and $r$, are constant quantities, and $r=100$, $a=2 \cdot 7 ; b=1.04$, and $c^{2}=76 ; x$ being variable, and the sine of incidence to radius as 100 .

Third Serics. Vol. 1. No. 3. Sept. 1832. 


\section{$178 \mathrm{Mr}$. Potter on a new Photometer by Comparison, and}

The great difference in intensity between the dark and the bright rings which we here find, is certainly not to be accounted for on any principles of interference yet proposed; and it furnishes a very strong argument against the undulatory theory, in which the effects of interference are supposed to be perfectly determinate when we know the circumstances of the interfering pencils.

Dr. Young and Sir John Herschel have each given formulæ for this difference of intensity, which, it is important to know, nearly coincide; the slight difference between them arising only from the latter having introduced certain approximations to simplify the expressions he used.

Sir John Herschel has deduced his formula from the rules laid down by the late M. Fresnel; and he finds that the minimum of the light in the dark ring should be represented by the expression $1 \cdot-4 a$, when the maximum of the light in the bright one is represented by 1 , and $a$ is equal to the first reflection, and the light incident equal to unity.

Taking the value of $a=\frac{1}{30}$ th, we have $1-\frac{4}{30}=1 \cdot-13=\cdot 8 \dot{6}$

$$
\text { and } \cdot 8 \dot{6}: 1 \cdot:: 1 \cdot: 1 \cdot 1538
$$

or the intensity of the light in the bright rings should be to that in the dark ones, as $1 \cdot 1538$ to 1 , a result widely different from 3.5 to $\mathrm{I}$, as we have found by experiment.

The great effect which we find to be produced by the interference of a small portion of light, must be deducible from any theory which is proposed as representing the true law in nature; and as a determined fact, it refutes an argument which M. Fresnel advanced against the hypothesis, that the fringes produced by the edges of bodies placed in a pencil of light diverging from a luminous point, are caused by the interference of light which has suffered an evanescent reflection with that which has arrived directly from the luminous point.

I have applied the photometer also, to repeating M. Arago's experiment, by which he has demonstrated that if the reflected and transmitted rings could be superposed they would exhibit a sensibly uniform light. I find this to be undoubtedly the fact; and the experiment furnishes an excellent means of trying the suitableness of the weather for using the photometer, and also the fitness of the locality where we purpose to experiment.

When I had completed the photometer, I found it very readily applicable to measuring the reflective powers of substances, of which we could never expect to procure sufficient extent of surface to render the method of photometry by lamps available: it requires only a very small extent of plane sur- 
on some Applications of it to important Optical Phanomena. 179

face to perform an accurate experiment with the comparative photometer.

For this purpose it is necessary to remove one of the pieces of crown-glass of the former experiment, and to place in lieu of it the substance to be examined, which has been before properly mounted, and then to find the incidence at which a similar surface on the piece of crown-glass gives an equal reflection. In this manner the larger facet of the diamond in a ring gave me the following results. The results in the first Table I obtained before the instrument was well adapted to the purpose; those in the second, which were obtained afterwards, I consider to be more correct.

\section{I.}

\begin{tabular}{|c|c|c|}
\hline $\begin{array}{l}\text { Incidence } \\
\text { on } \\
\text { Diamond }\end{array}$ & $\begin{array}{l}\text { Corre- } \\
\text { sponding } \\
\text { Incidence } \\
\text { on Crown- } \\
\text { glass. }\end{array}$ & $\begin{array}{l}\text { Diamond } \\
\text { reflects of } \\
\text { every } 100 \\
\text { Rays } \\
\text { incident. }\end{array}$ \\
\hline $10^{\circ}$ & $65^{\circ} 0^{\prime}$ & 10.00 \\
\hline 20 & 650 & $10 \cdot 00$ \\
\hline 30 & 670 & $11 \cdot 15$ \\
\hline 30 & $\begin{array}{ll}65 & 18\end{array}$ & $10 \cdot 15$ \\
\hline 40 & $\begin{array}{ll}68 & 48\end{array}$ & $12 \cdot 43$ \\
\hline 50 & $74 \quad 0$ & $18 \cdot 16$ \\
\hline 60 & $\begin{array}{ll}78 & 12\end{array}$ & 26.80 \\
\hline 70 & 79 18 & $30 \cdot 05$ \\
\hline
\end{tabular}

II.

\begin{tabular}{|c|rr|c|}
\hline $\begin{array}{c}\text { Incidence } \\
\text { on } \\
\text { Diamond. }\end{array}$ & $\begin{array}{c}\text { Corre- } \\
\text { sponding } \\
\text { Incidence } \\
\text { on Crown- } \\
\text { glass. }\end{array}$ & $\begin{array}{c}\text { Diamond } \\
\text { reflects of } \\
\text { every 100 } \\
\text { Rays } \\
\text { incident. }\end{array}$ \\
\hline $3^{\circ}$ & $63^{\circ} 48^{\prime}$ & $9 \cdot 4.1$ \\
10 & 63 & 48 & $9 \cdot 41$ \\
10 & 63 & 24 & $9 \cdot 23$ \\
20 & 64 & 48 & $9 \cdot 89$ \\
20 & 64 & 36 & $9 \cdot 79$ \\
30 & 67 & 0 & $11 \cdot 15$ \\
30 & 65 & 42 & $10 \cdot 37$ \\
30 & 66 & 42 & $10 \cdot 96$ \\
40 & 71 & 12 & $14 \cdot 62$ \\
40 & 70 & 0 & $13 \cdot 4.4$ \\
50 & 74 & 18 & $18 \cdot 63$ \\
50 & 73 & 42 & $17 \cdot 72$ \\
60 & 76 & 0 & $21 \cdot 65$ \\
60 & 75 & 36 & $20 \cdot 87$ \\
70 & 79 & 0 & $29 \cdot 11$ \\
70 & 77 & 42 & $25 \cdot 48$ \\
\hline
\end{tabular}

These results are important, as we may compare them with the formula which has the uniform approbation of those who adopt the undulatory theory of light. The unanimous conclusion of Dr. Young, M. Poisson, and M. Fresnel, who have each investigated the subject, was, that the intensity of the perpendicular reflection, according to that theory, should be equal to $\left(\frac{\mu^{\prime}-\mu}{\mu^{\prime}+\mu}\right)^{2}$; and knowing the value of $\mu^{\prime}$, or the refractive index for diamond, we find that this reflection ought, if the undulatory theory were true, to be about the double of 
what it is in fact. 'Taking $\mu^{\prime}=2 \cdot 5$, we find $\frac{2 \cdot 25}{12 \cdot 25}$, or 18.36 rays should be reflected of every 100 incident; whilst experiment shows it to be only somewhat more than 9 , and perbaps about $9 \cdot 3$.

I have applied the photometer to a few other substances, and the results of my observations are given in the following Table.

\begin{tabular}{|c|c|c|c|c|}
\hline Substance examined. & Incidence. & \begin{tabular}{|l} 
Correspol \\
Incidenc \\
Crown-g
\end{tabular} & $\begin{array}{l}\text { inding } \\
\text { ce on } \\
\text { glass. }\end{array}$ & $\begin{array}{l}\text { Reflected of } \\
\text { every } 100 \\
\text { Rays incident }\end{array}$ \\
\hline Mica ....... & $5^{\circ}$ & $20^{\circ}$ & & $3 \cdot 83$ \\
\hline Do. . . . . . & 5 & 19 & & $3 \cdot 80$ \\
\hline Do. . . . . . & 20 & 25 & & 4.01 \\
\hline Do. . . . . & 20 & 25 & & $3 \cdot 99$ \\
\hline Do. $\ldots \ldots$ & 30 & 34 & 0 & $4 \cdot 38$ \\
\hline Do. . . . . . & 30 & 35 & 0 & $4 \cdot 43$ \\
\hline Do.(another piece) & 5 & 23 & & $3 \cdot 92$ \\
\hline Do. . . . . & 5 & 19 & 0 & $3 \cdot 80$ \\
\hline Selenite . . . & 3 & 3 & 0 & $3 \cdot 49$ \\
\hline Do. $\ldots \ldots$ & 5 & 10 & $\mathbf{0}$ & $3 \cdot 60$ \\
\hline Do. $\ldots \ldots \ldots$ & 45 & 45 & 0 & $5 \cdot 20$ \\
\hline Do.(another piece) & 5 & 5 & 0 & $3 \cdot 52$ \\
\hline Do. $\ldots \ldots$ & 20 & 20 & 0 & $3 \cdot 83$ \\
\hline Iceland spar . . . & 5 & 19 & 0 & $3 \cdot 80$ \\
\hline Do. . . . . & 5 & 18 & 0 & $3 \cdot 78$ \\
\hline Do. . . . . . & 5 & 18 & 0 & $3 \cdot 78$ \\
\hline Do. $\ldots \ldots$ & 5 & 17 & 0 & $3 \cdot 75$ \\
\hline Do.(another piece) & 5 & 22 & 0 & $3 \cdot 89$ \\
\hline Do. . . . . & 5 & 22 & 0 & $3 \cdot 89$ \\
\hline Rock crystal . . . & 0 & 14 & 0 & $3 \cdot 68$ \\
\hline Do. $\ldots \ldots$ & 0 & 14 & 0 & $3 \cdot 68$ \\
\hline Do. $\ldots \ldots \ldots$ & 0 & 12 & 30 & $3 \cdot 65$ \\
\hline Do. $\ldots \ldots \ldots$ & 0 & 16 & 0 & $3 \cdot 73$ \\
\hline Do. (another piece) & 5 & 12 & 0 & $3 \cdot 64$ \\
\hline Do. . . . . & 10 & 14 & 0 & $3 \cdot 68$ \\
\hline Amethyst $\ldots$. & 5 & 20 & 0 & $3 \cdot 83$ \\
\hline Do. .... & 5 & 22 & 0 & $3 \cdot 89$ \\
\hline Emerald . . . . & 10 & 22 & 0 & $3 \cdot 89$ \\
\hline Do. . . . . . & 10 & 24 & 0 & $3 \cdot 95$ \\
\hline Do. . . . & 30 & 40 & 0 & $4 \cdot 76$ \\
\hline Do. . . . . & 30 & 40 & 0 & $4 \cdot 76$ \\
\hline
\end{tabular}

The natural surfaces, and as recent as possible for mica, selenite, and Iceland spar, were used in all the above, except- 
ing in amethyst and emerald; and $I$ have also less confidence in the measurements for these two substances than for the others. The mica, selenite, Iceland spar, and rock crystal, were covered with a varnish of black sealing-wax on their second surfaces, to prevent reflection. Where it is said that the incidence on rock crystal was perpendicular, it must be understood that it was only so nearly so, that the natural unevenness of the facet made it impossible to determine it.

The reflection by selenite is so exceedingly nearly the same as that of crown-glass, that I found it impossible to state with certainty whether it was higher or lower: in one observation, however, I made it higher.

With the other substances, and particularly with mica and Iceland spar, the difference is quite obvious at the first view.

XXXIX. On the Establishment of some perfect System of Chemical Symbols; with Remarks on Professor Whewell's Paper on that Subject. By Mr. R. Warington*.

$\mathrm{IN}$ entering upon the consideration of the necessity of chemical symbols, - a necessity which becomes the more urgent from the rapid progress the science is continually making, and from the increasing number of new combinations which are daily brought before our notice, and the want of some system of symbols to facilitate our reasoning upon these and other combinations, - there are two great points to be kept in view; namely, brevity and clearness in the nature of the symbols themselves, and as perfect an approximation to mathematical consistency and algebraic formulæ as the nature of the subject will admit.

Professor Whewell, in a paper upon this subject published in the 1st volume of the Journal of the Royal Institution for May 1831, advocates the necessity of radically altering the symbolic system of Berzelius, on account of its total want of mathematical propriety, and fully demonstrates the advantages to be derived from the adoption of an arrangement founded on algebraic principles $\%$.

The improprieties more particularly pointed out in Berzelius's system of notation are; first, the method adopted by him of connecting the elementary symbols together in representing compound bodies, as though, according to the notation made use of in algebraic reasoning, the constituents were multiplied by each other; whereas the combination is effected by

* Communicated by the Author.

$\dagger$ In the Phil. Mag. and Annals, N.S., vol. x. p. 104, appeared a paper on Chemical Symbols and Notation by Mr. Prideaux, in reply to Professor Whewell, a brief rejoinder from whom will be found in the same volume. p. 405, note.-EDIT. 